\title{
Development of Continuous Speed Profile Using GPS at Johor Federal Roads F0050
}

\author{
Joewono Prasetijo ${ }^{1, a}$ and Zaffan Farhana Zainal ${ }^{1}$ \\ ${ }^{1}$ Faculty of Civil and Environmental Engineering, Universiti Tun Hussein Onn Malaysia, 86400 Parit Raja, Johor, \\ Malaysia
}

\begin{abstract}
Road accidents are one of the most relevant issues in today's society. It causes hundreds of accidents every year from over the world. Every year 1.2 million of people are killed and between 20 and 50 million people are offended due to the road accidents. Three main types of accidents in Malaysia is collision with passenger cars, collisions with other motorcycles and single-motorcycle accidents. F0050 is ranked the district with the highest road fatalities in Johor for five consecutive years. Motorcyclists and their pillion riders were the highest contributors $-60 \%$ or 648 fatalities, followed by car drivers and passengers numbering 266 fatalities. One reason of accident occurrence can be lack of road design consistency which most drivers make fewer errors in the vicinity of geometric features. Geometric design consistency is emerging as an important component in highway design relate to the safety performance. The result shows the continuous speed profiles along F0050. Since motorcyclist have a higher fatality per distance traveled, this study will develop the potential relationship between design consistency which is represented by continuous speed profiles by using Global Positioning System (GPS).
\end{abstract}

\section{Introduction}

Nowdays, road accidents are one of the most relevant issues in society. It causes hundreds of accidents every year from over the world. Every year 1.2 million of people are killed and between 20 and 50 million people are offended due to the road accidents. If these trends continue, road traffic accidents are will be predicted to be the third important to contributed to the global burden of disease and injury by 2020 . Among ASEAN countries [1,2], Malaysia has the highest road fatality and more than $50 \%$ of the road accident fatalities involved motorcyclist that represent more than two thirds of road accident victims. About 300000 accidents reported and 1\% of it is fatal accidents in Malaysia for every year. Motorcyclist is the main vehicle in Malaysia that contributes about $55 \%$ of all registered vehicle in Malaysia. The potential to exposure in road accident are highest among the user of motorcycle because it directly exposed and come in direct contact with the impacting vehicles or obstacle during a collision and resulting in severe injuries and fatality [3]. Based on previous study, accidents that occur either car driver or motorcyclist was not injured but the injured parties is either passengers or the occupants of the other vehicle around $97 \%$ of motorcyclist were injured or killed in these collisions compared with $50.5 \%$ of car drivers. It also stated that at higher speed motorcycles

\footnotetext{
${ }^{a}$ Corresponding author : joewono@uthm.edu.my
} 
and car collision than car and car collisions motorcyclist involved were $95.4 \%$ likely to be injured while car drivers were $0.9 \%$ likely to be injured [4]. Mainly, motorcyclist is 17 times more dangerous than passengers car and also the motorcyclist will be in front of higher risk of injury or fatality because the level of exposure to injury is higher if compared to other vehicle such a passenger car in accident [5]. The reason why road accident keep rising in Malaysia because one of the lack of road geometric design consistency where the drivers make a fewer errors due to the road geometric features. If the consistency are poor, the potential for accident happen are highest $[6,7]$. Geometric design consistency is emerging as an important component in highway design relate to the safety performance. Geometric design is influenced by the vehicle, drivers and traffic characteristics. Geometric design elements that influence traffic operations include number and width of lanes, the presence and widths of shoulders and highway medians, and the horizontal and vertical alignment of the highway.

The importance of design consistency and its contribution to road safety can be justified based on interaction between driver, vehicle and roadway interaction. Most consistency concepts today deal with the variation of vehicles speed but less variation types (heterogeneous) on road section and this speed variation is affected mainly by horizontal alignment and vertical alignment of roads [2, 6, 7]. Design consistency is measured by estimating the speed variation along successive geometric elements and evaluation of the speed deviation from the average speed [8]. A road that has a good level of consistency can affect the driver to drive in a stable and careful. While for the poor level of consistency, can affect high speed along a different path among different drivers and can cause accidents. Operating speeds profile is used to assess the design consistency by identifying locations with speed variability between geometric design/features and crash rate. Some previous studies estimated consistency of horizontal alignment.

\section{Method}

In many years, the use of Global Positioning System (GPS) technologies has used to perform traffic data collection for transportation studies. In transportation engineering, GPS devices has been frequently used in study of travel time, route choice, car following and behaviors' of driver speed. By previous studies, most of them measure speed using automated traffic counters or radar speed gun measurement at specific points along the segment by assuming it representative of the speeds along the segment. But this assumption not is able when the road has different geometric elements that can affect vehicle speed. The data collected with the GPS device contains highly accurate measurements of the test vehicle's position and speed at each second in time. GPS data can also be utilized to calculate the values of other traffic measures related to work zone traffic conditions, including average travel speeds, deceleration and acceleration rates, traffic delays, and vehicle queue lengths [9]. The GPS device was configured to record the vehicle positions and speeds at one-second time intervals. Two persons, a driver and a GPS recorder, were needed to perform the data collection. The average vehicle travel speed along distance traveled are be measured by GPS at every segment. Based on previous study [10], they suggested at least $300 \mathrm{~m}$ from the study site to any intersection or other element or stop sign that may affecting operating speeds.

According to [8], continuous speed profiles are used to determine the global speed variation along a road segment and determining a single consistency value for the whole road segment. Parameters for this model are the bounded area between the profile and the average speed along a two-lane highway segment. As a design consistency increased, crash rates will shown to decrease significantly. Refer Equations (1): Ra is defining as the normalized relative area (per unit length) bounded among the speed profile and the average speed line. It can be practical use to individual speed profile or to the operating speed profile. First, calculate the average speed of the speed profile along the segment of road. Next, the areas bounded between the speed profile and the average speed lines were calculated $\left(a_{i}\right)$. The consistency measure is the sum of the areas divided by the length of the segment $(\mathrm{L})$. 


$$
\mathrm{Ra}=\frac{\left(\sum a_{i}\right)}{L}
$$

where, $\mathrm{Ra}=$ relative area $(\mathrm{m} / \mathrm{sec})$ measure consistency, $\Sigma a_{i}=$ sum of $\mathrm{i}$ areas bounded between the speed profile and the average speed $\left(\mathrm{m}^{2} / \mathrm{sec}\right)$, and $\mathrm{L}=$ entire segment length $(\mathrm{m})$.

\section{Site Selection}

The study was conducted at Johor Federal Roads. The roads consist of two lanes rural which is the road at F0050 (Batu Pahat-Kluang).The road Batu Pahat-Kluang (F0050) is the main road connecting two cities in Johor. In this study, Figure 1 shows the area of study, the data are record starting intersection at KM5 until intersection Ayer Itam at KM32. According to the Star, reported on October 2, 2013 [11], based on Road Safety Department, F0050 is ranked the district with the highest road fatalities in Johor for five consecutive years. Motorcyclists and their pillion riders were the highest contributors $-60 \%$ or 648 fatalities, followed by car drivers and passengers numbering 266 fatalities.

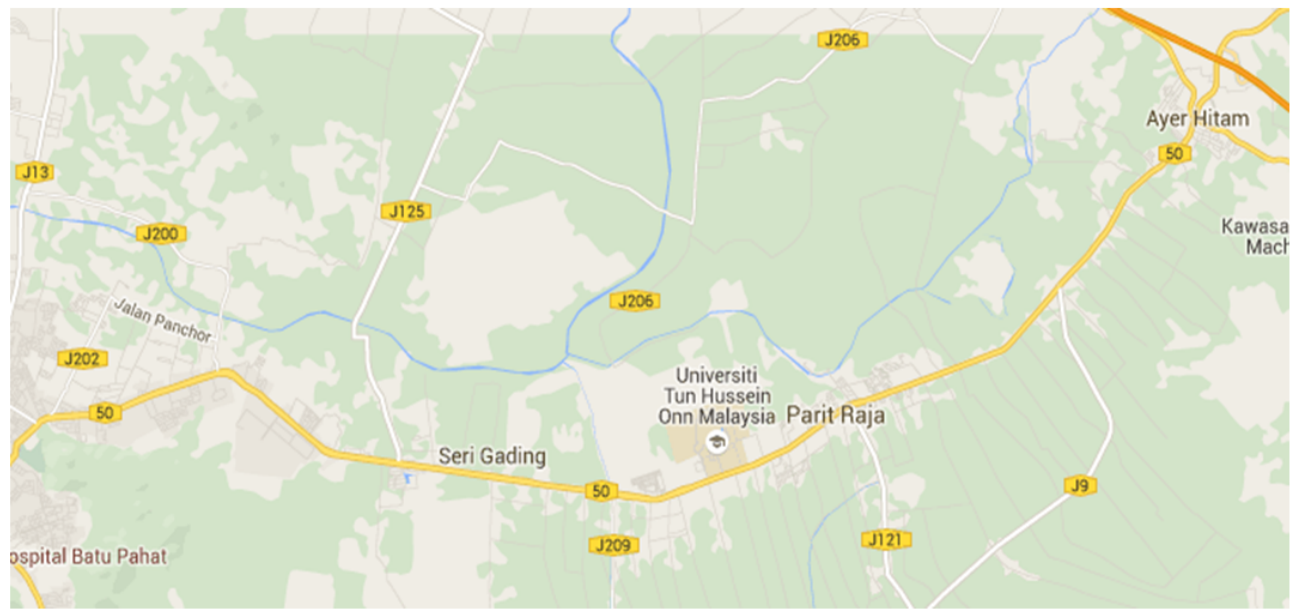

Figure 1. Area study.

\section{Results and Discussion}

Speed data were collected in the traffic stream under free - flow conditions along the study area using GPS which is primary data. The consideration in selection it should be free to avoid zero speed. The data should consider every elements of road design (geometric); lane width, shoulder width, access point/density access point which may not the same along the segment. The constantly geometric features will change along the segment, according to environmental conditions and it will cause changes in vehicles speed. Table 1 shows a summary of secondary data that included of road geometric, traffic information and accident information.

Data was collected on weekdays during off-peak hours where it more free flow traffic and the duration is selected to avoid from peak hour in morning and the evening. The test drivers were instructed to drive the equipment; GPS along the segment. Figure 2 shows the average speed of vehicle along the segment. The average speed was calculated as the sum of all speeds that divided by the number of speed observation. In this case, the average speeds of vehicles based on the data taken by GPS. The average length is $25 \mathrm{~km}$. The GPS was used to obtain the continuous speed vehicles. Figure 3[12] shows the example of speed profile and consistency measured. Operating speed profile was plotted for each travel direction. The starting point of the analysis was the prediction of speeds 


\section{MATEC Web of Conferences}

that depending on the geometric characteristics along the segment. The independent measures was proposed to evaluate consistency; the relative area bounded by the speed profile.

Table 1. A summary of secondary data.

\begin{tabular}{|c|c|c|c|}
\hline \multicolumn{2}{|r|}{ Variable } & Type & Description \\
\hline Dependent & Accident Crashes & Count & $\begin{array}{c}\text { Type of accident crashes (Fatal, Serious, Minor, } \\
\text { Wreckage) }\end{array}$ \\
\hline Independent & AADT & Continuous & Average annual daily traffic per $\mathrm{km}$ \\
\hline Independent & Traffic flow & Continuous & $\begin{array}{l}\text { Average daily traffic including all motorized forms } \\
\text { of traffic (i.e. motorcycles, cars, bus, trucks) }\end{array}$ \\
\hline Independent & Lane width & Continuous & Lane width (ranging from $3.5 \mathrm{~m}$ to $3.7 \mathrm{~m}$ ) \\
\hline Independent & Shoulder width & Continuous & Road shoulder width (ranging from 0 to $2.4 \mathrm{~m}$ ) \\
\hline Independent & Roadside hazard rating & Qualitative & Scale ranging from (1 (best) to 7 (worst)) \\
\hline Independent & Median width & Continuous & Median width (ranging from 3.5 to $9.0 \mathrm{~m}$ ) \\
\hline Independent & No. of lanes & Count & Total no. of lanes in the direction of travel \\
\hline Independent & Land use & Qualitative & $\begin{array}{c}\text { Level of activity along roadway (1 for no activity } \\
\text { level, } 2 \text { for low activity level (e.g. school, factory), } \\
3 \text { for high activity level (e.g., residential or } \\
\text { commercial) }\end{array}$ \\
\hline Independent & Access density & Count & $\begin{array}{l}\text { Number of intersection and minor access points per } \\
\text { km along roadway }\end{array}$ \\
\hline Independent & Horizontal alignment & Continuous & Horizontal curvature $(1 / \mathrm{km})$ \\
\hline Independent & Vertical alignment & Qualitative & $\begin{array}{l}\text { Indicator of vertical slope along road's length (1 for } \\
\text { flat, } 2 \text { for rolling/undulating) }\end{array}$ \\
\hline
\end{tabular}

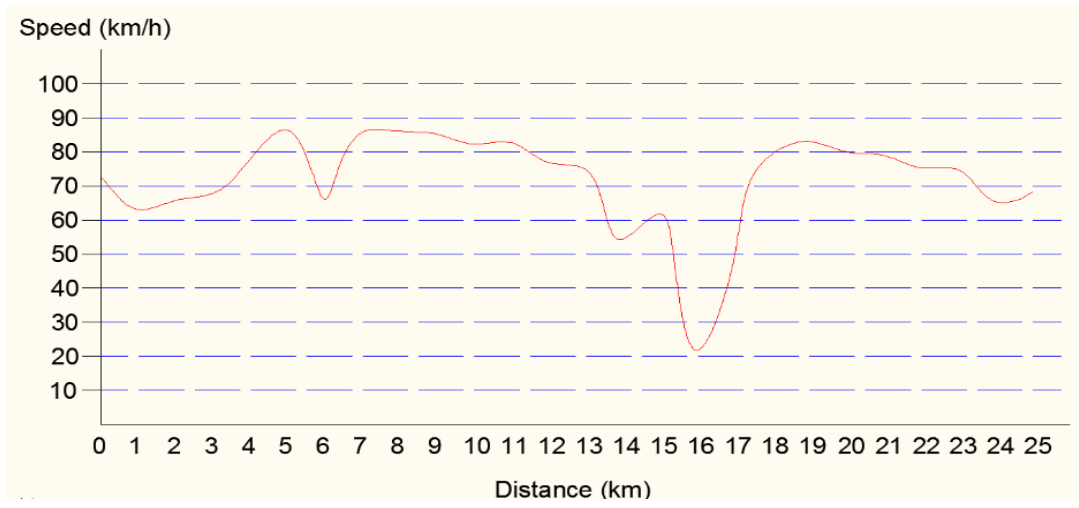

Figure 2. Average speed profile.

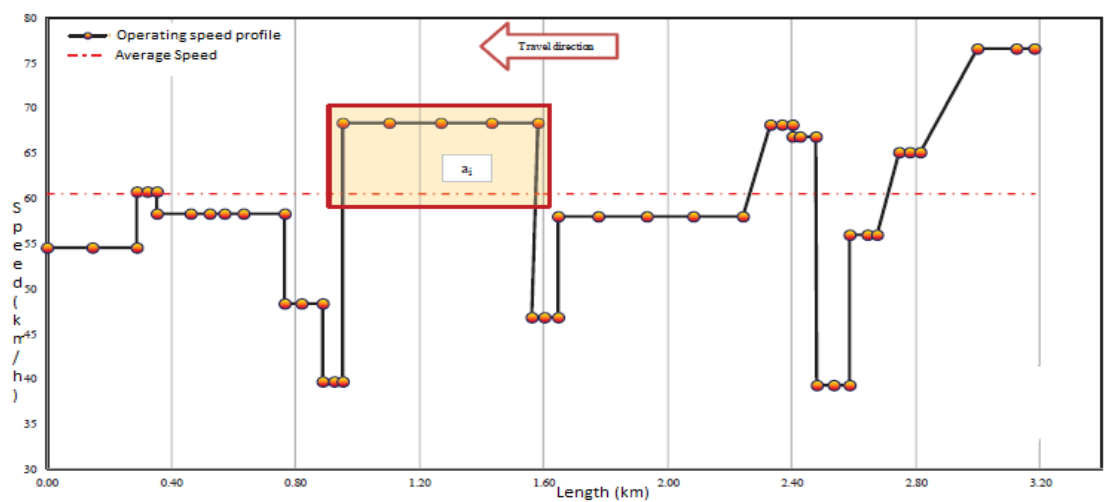

Figure 3. Example of speed profile and consistency measures. 
Figure 4 shows the linear speed profile of vehicle along the road segment. The design consistency parameter will based on continuous operating speed profile models. The Ra was calculated based on speed profile along the road. Analysis of road design consistency is a good way to reduce road accident. The design consistency parameter will based on continuous operating speed profile models. The advantages of operating speed profile are based on continuous data but not based on speed-spot data collection. A plot of the $85^{\text {th }}$ percentile operating speeds along the segment provided the "speed profile" under free-flow condition. Plot the $85^{\text {th }}$ percentile speed based on average speed along the road. The $85^{\text {th }}$ percentile speed was predicted based on such independent parameters as the degree of curve, length of curve, and the deflection angle. The concern of this study is the horizontal alignments which consist of the straight line. The $85^{\text {th }}$ percentile values were obtained from real speed for each data through analysis. The profiles were plotted for observed $85^{\text {th }}$ percentile values for real speed in each through along the segment. Speed prediction model was utilized in the present study for the development of the speed profile.

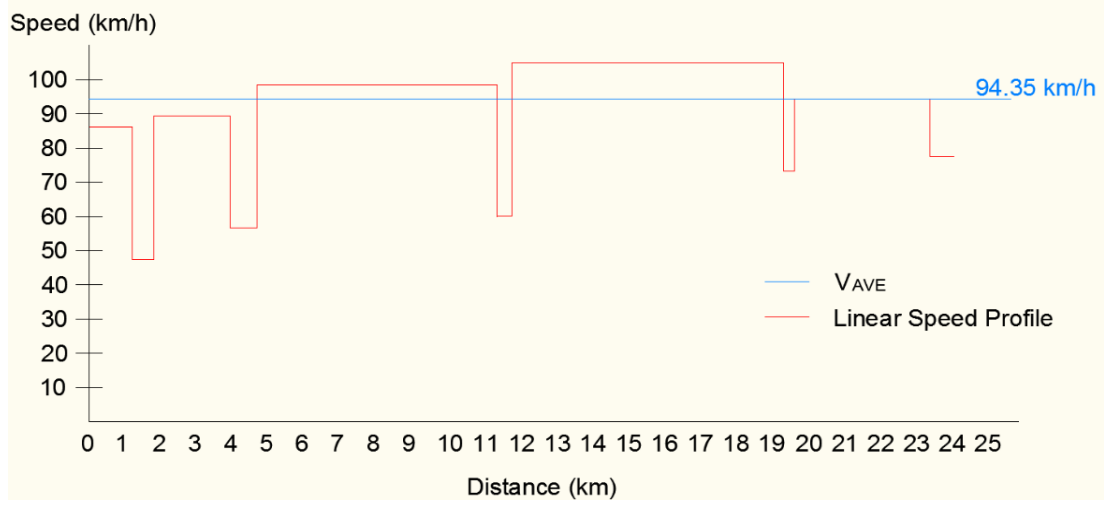

Figure 4. Linear speed profile.

\section{Conclusions}

Road accidents cause a thousand of victims in every year on the road. The outcomes from this study are valuable and can be used to implement and can be important role in designing or redesigning to reduce the road accident among motorcyclist and cars that occur in Johor Federal Roads especially F0050 (BatuPahat - Kluang). By using GPS devices, vehicles are recorded for every second over an entire trip at any time of day and any under weather condition. It does not need to assume that vehicle speeds at one location are representative of speed along the entire segment and also using GPS devices, able generate continuous speed profiles. After collecting data and road segmentation, the next step is to develop $85^{\text {th }}$ percentile speed profile which is required for developing the consistency model. An average of $85^{\text {th }}$ percentile speed will be presented at every road segment. Estimation of geometry for consistency in design is approach for enhancing safety in Johor Federal Roads.

\section{Future Work}

The study is still ongoing. There are some parts of the analysis have not been obtained. After the speed profile along the segment, area boundary between motorcycles and cars will be calculate to find the design consistency of the road. Combining the results on the road consistency with accidents frequency along the sections, it is expecting to produce the relationships between accidents frequency and road design consistency. Therefore, applying Poisson distribution in modeling is to overcome the shortcoming of conventional regression model. The last findings of the study that model will illustrate relationship between design consistencies and expected number of motorcycles and other vehicle 
(cars) crashes along the road over the years. The findings in identification of hazardous location for motorcycles will become the effective countermeasures to reduce crash frequency and severity of motorcyclist, in term of road design and traffic behavior.

\section{Acknowledgement}

The authors would like to thank all individuals and organization that have made this study possible. Thank you is also extended to the authorities of Faculty of Civil Engineering and Environment, Universiti Tun Hussein Onn Malaysia.

\section{References}

[1] M.M.A. Manan and A. Várhelyi, Motorcycle fatalities in Malaysia, IATSS Research, 36(1), 3039, (2012).

[2] F.J.C. Torregrosa, P.Z. Ana Maria and G.G. Alfredo, New geometric design consistency model based on operating speed profiles for road safety evaluation, Interm Report, (2011).

[3] S.M.R. Sharifah Allyana, H.Z. Zarir, A.M. Abdul Rahmat, M.F. Siti Atiqah, F.P. Noor, S.V. Wong and M.J. Jamilah, Recent trend of fatal motorcycle crashes in Malaysia, Proc. of the 8th International Forum of Automotive Traffic Safety, (2010).

[4] D. Hung, M. Stevenson and R. Ivers, Prevelance of helmet use among motorcycle riders in Vietnam, Injury Prevention, 409-413, (2006).

[5] U. Radin, Updates of road safety status in Malaysia, IATSS Research, 29, 78-80, (2005).

[6] R. Lamm, B. Psarianos and T. Mailaender, Highway Design and Traffic Safety Engineering Handbook, (1999).

[7] J. De Oña and L. Garach, Accidents prediction model based on speed reduction on spanish twolane rural highways, Procedia-Social and Behavioral Sciences, 53, 1010-1018, (2012).

[8] C. Mattar-Habib, A. Polus and H. Farah, Further evaluation of the relationship between enhanced consistency model and safety of two-lane rural roads in Israel and Germany, European J. of Transport and Infrastructure Research, 4(8), (2008).

[9] Y. Jiang and S. Li, Measuring and analyzing vehicle position and speed data at work zones using global positioning systems, ITE J., 72(3), 48-53, (2002).

[10]K. Schurr, P. McCoy, G. Pesti and R. Huff, Relationship of design, operating, and posted speeds on horizontal curves of rural two-lane highways in Nebraska, Transportation Research Record: J. of the Transportation Research Board, 1796, 60-71, (2002).

[11]C. Tan, Batu Pahat ranked highest in road fatalities, The Star, (October 2, 2013). < retrieved from http://www.thestar.com.my> (assessed on July 27, 2015).

[12]F. Russo, R. Mauro and G. Dell'Acqua, Rural highway design consistency evaluation model, Procedia-Social and Behavioral Sciences, 53, 952-960, (2012). 